\title{
The Danish Collaborative Bacteraemia Network (DACOBAN) database
}

This article was published in the following Dove Press journal:

Clinical Epidemiology

18 September 2014

Number of times this article has been viewed

\author{
Kim Oren Gradel ${ }^{1,2}$ \\ Henrik Carl Schønheyder ${ }^{3,4}$ \\ Magnus Arpi ${ }^{5}$ \\ Jenny Dahl Knudsen ${ }^{6}$ \\ Christian $Ø$ stergaard $^{6}$ \\ Mette Søgaard ${ }^{7}$
}

For the Danish

Collaborative Bacteraemia

Network (DACOBAN)

'Center for Clinical Epidemiology,

Odense University Hospital, ${ }^{2}$ Research

Unit of Clinical Epidemiology, Institute

of Clinical Research, University

of Southern Denmark, Odense,

Denmark; ${ }^{3}$ Department of Clinical

Microbiology, Aalborg University

Hospital, ${ }^{4}$ Department of Clinical

Medicine, Aalborg University, Aalborg,

${ }^{5}$ Department of Clinical Microbiology,

Herlev Hospital, Copenhagen

University Hospital, Herlev,

${ }^{6}$ Department of Clinical Microbiology,

Hvidovre Hospital, Copenhagen

University Hospital, Hvidovre,

${ }^{7}$ Department of Clinical Epidemiology, Institute of Clinical Medicine, Aarhus

University Hospital, Aarhus University,

Aarhus, Denmark

Correspondence: Kim Oren Gradel

Center for Clinical Epidemiology, Odense

University Hospital, Entrance I0I, 4th

floor, 29 Sønder Boulevard, Odense

5000, Denmark

Tel +45 2I I58 085

Fax +4565917264

Email kim.gradel@rsyd.dk
Abstract: The Danish Collaborative Bacteraemia Network (DACOBAN) research database includes microbiological data obtained from positive blood cultures from a geographically and demographically well-defined population serviced by three clinical microbiology departments (1.7 million residents, $32 \%$ of the Danish population). The database also includes data on comorbidity from the Danish National Patient Registry, vital status from the Danish Civil Registration System, and clinical data on $31 \%$ of nonselected records in the database. Use of the unique civil registration number given to all Danish residents enables linkage to additional registries for specific research projects. The DACOBAN database is continuously updated, and it currently comprises 39,292 patients with 49,951 bacteremic episodes from 2000 through 2011. The database is part of an international network of population-based bacteremia registries from five developed countries on three continents. The main purpose of the DACOBAN database is to study surveillance, risk, and prognosis. Sex- and age-specific data on background populations enables the computation of incidence rates. In addition, the high number of patients facilitates studies of rare microorganisms. Thus far, studies on Staphylococcus aureus, enterococci, computer algorithms for the classification of bacteremic episodes, and prognosis and risk in relation to socioeconomic factors have been published.

Keywords: bacteremia, database, positive blood cultures, population-based

\section{Introduction}

Bacteremia is a serious condition, with a 30 -day mortality of $15 \%-30 \%$ and ranked among the top-seven causes of death in developed countries. ${ }^{1}$ The term "bacteremia" also covers fungemia, and is defined as the presence of bacteria or fungi in the bloodstream associated with clinical symptoms, distinguishing it from blood contamination., ${ }^{2,3}$ In practical terms, bacteremia is based on the detection of bacteria or fungi in blood cultures (BCs) ordered on suspicion of a possible bloodstream infection in an ill patient. The distinction between bacteremia and blood contamination requires due consideration. However, the most effective means of capturing all data is the electronic recording of bacteria and fungi in $\mathrm{BCs}$, as performed by clinical microbiological laboratories. ${ }^{2}$

The Danish Collaborative Bacteraemia Network (DACOBAN) database is a research database compiled from administrative data. The main purpose of the database is to provide Danish population-based bacteremia data for studies related to surveillance, risk, and prognosis. DACOBAN covers $32 \%$ of the Danish population, and is part of a multinational bacteremia collaborative network that incorporates bacteremic data from all of Finland, as well as geographically and demographically well-defined regions in Canada, Australia, and Sweden., 


\section{Compilation of the study database Linkage between data sources}

All Danish residents have a unique personal identification number (the civil registration number) used in all administrative registries, which enables their linkage. ${ }^{6}$ Date of birth and sex are incorporated into this number.

\section{Core data set}

The core data set consists of microbiological data on all positive BCs from the clinical microbiology departments at the three hospitals in Aalborg, Herlev, and Hvidovre (Table 1), which use the same laboratory information system (ADBakt; Autonik, Sköldinge, Sweden). The data are derived from patients with a civil registration number (ie, Danish residents), which comprise $99.5 \%$ of all positive BCs. BCs are rarely ordered by physicians outside the hospital setting, but if they are, they are normally collected in the outpatient area at the nearest hospital and are thereby captured by the DACOBAN database. All departments use automated BC systems (Bactec $^{\mathrm{TM}}\left[\mathrm{BD}\right.$, Franklin Lakes, NJ, USA] or BacT/Alert ${ }^{\circledR}$ [bioMérieux, Marcy l'Etoil, France]) and conventional identification methods, ${ }^{7}$ possibly supplemented with automatic methods, such as Vitek ${ }^{\circledR} 2$ (bioMérieux) or MALDI-TOF (Bruker, Bremen, Germany).

\section{Linkage between the core data set and other registries}

The Danish National Patient Registry (DNPR) includes all hospital diagnoses and surgical procedures from 1977 onward. ${ }^{8}$ The DNPR comprises inpatients from the whole period, and outpatients and emergency visits since 1995. As all data are received electronically from the hospitals' patient administrative systems, the DNPR is updated shortly after discharge of the patient. For patients in the DACOBAN database, we have access to their hospital history since 1977, including information on number and length of admissions, minor and major surgical procedures, and specific disease entities.

The Danish Civil Registration System, which was implemented in 1968, is updated daily. ${ }^{6}$ This registry contains information on the patients' vital status, including date of death, disappearance, or emigration if relevant. In addition to linkage to other health registries, physicians at the three clinical microbiology departments prospectively record additional clinical variables for the DACOBAN, as outlined in the following sections.

\section{Survey frequency}

The DACOBAN database receives core data when physicians at the three clinical microbiology departments validate the laboratory data. Currently, the DACOBAN database includes all of 2011, and future updates are expected for full years 6-12 months after their expiry, from the laboratories, the DNPR, and the Danish Civil Registration System. The latest date of the patients' vital status derived from the Danish Civil Registration System ${ }^{6}$ is September 27, 2012.

\section{Data-resource area and population coverage}

The Danish tax-funded welfare system provides free access to health care by general practitioners and at public hospitals.

Table I Hospital and population data

\begin{tabular}{|c|c|c|c|c|c|}
\hline DCM at & Hospitals $^{\mathbf{a}}$ & $\begin{array}{l}\text { One blood- } \\
\text { culture set }\end{array}$ & $\begin{array}{l}\text { Blood-culture } \\
\text { system }\end{array}$ & Area (years) & $\begin{array}{l}\text { Population } \\
\text { (year) }^{\mathrm{b}}\end{array}$ \\
\hline \multirow[t]{2}{*}{ Aalborg Hospital } & $4(1,347)^{c}$ & Children: $1 \times 10 \mathrm{~mL}$ & BacT/Alert & County of North Jutland (2000-2006) & $494,153(2000)$ \\
\hline & & Adults: $3 \times 10 \mathrm{~mL}$ & & North Denmark Region (2007-20II) & $580,293(2011)^{d}$ \\
\hline \multirow[t]{2}{*}{ Herlev Hospital } & $3(1,587)$ & Children: $1 \times 10 \mathrm{~mL}$ & Bactec & Copenhagen County (2000-2006) & $613,444(2000)$ \\
\hline & & Adults: $2 \times 10 \mathrm{~mL}$ & & $\begin{array}{l}\text { Capital Region, corresponding to the } \\
\text { former Copenhagen County (2007-20II) }\end{array}$ & $648,449(2011)^{e}$ \\
\hline \multirow[t]{2}{*}{ Hvidovre Hospital } & $5(1,639)$ & Children: $1 \times 10 \mathrm{~mL}$ & BacT/Alert & $\begin{array}{l}\text { Copenhagen municipality, Frederiksberg } \\
\text { municipality, Bornholm regional } \\
\text { municipality (2000-2006) }\end{array}$ & $630,462(2000)$ \\
\hline & & Adults: $2 \times 10 \mathrm{~mL}$ & & $\begin{array}{l}\text { Capital Region, corresponding to the } \\
\text { former Copenhagen, Frederiksberg, and } \\
\text { Bornholm municipalities (2007-20II) }\end{array}$ & $690,146(2011)$ \\
\hline
\end{tabular}

Notes: aHospitals submitting blood cultures to the DCM; ' ${ }^{c}$ compiled from http://www.statistikbanken.dk (accessed August 5, 20I3); 'number of hospitals in 20II (beds in the hospitals in 2009, compiled from http://www.ssi.dk/Sundhedsdataogit/Dataformidling/Sundhedsdata/Sengepladser.aspx [accessed September 4, 20I3]); ${ }^{\text {services from }}$ DCM, Aalborg Hospital to Thy-Mors Hospital (catchment population 45,000, I46 beds) took effect in 20II; ethree municipalities (Søllerød, Værløse, Ledøje-Smørum) in Frederiksborg County before 2007 were merged with municipalities from Copenhagen County in 2007. The 6I,350 inhabitants of these municipalities (in 2006, data unavailable thereafter) were subtracted from the number of inhabitants in the Capital Region (excluding Copenhagen, Frederiksberg, and Bornholm municipalities). Manufacturer details are as follows: Bactec ${ }^{\top M}$ (BD, Franklin Lakes, NJ, USA), BacT/Alert ${ }^{\circledR}$ (bioMérieux, Marcy l'Etoil, France).

Abbreviation: DCM, Department of Clinical Microbiology. 
Only $1 \%$ of hospital beds are in the private sector, and these are used solely for elective admissions. The public health service has a regional structure, which is subject to change, with the most recent change occurring in 2007. Until 2007, Denmark was divided into 14 counties, which were reorganized into five regions. This reorganization had very little impact on the background population of the DACOBAN database, and almost none for the present Capital Region, but it led to a $17 \%$ increase in the population when North Jutland County was reorganized into the North Denmark Region. ${ }^{9}$ Population data can be obtained from Statistics Denmark (http://www.statbank.dk, in English) for the calculation of incidence data.

The admission of all acutely ill patients to the nearest public hospital in their region of residence and the submission of all of the hospitals' BCs to the three clinical microbiology departments prompts population-based coverage of the DACOBAN database..$^{10}$ However, the main Danish referral hospital (Rigshospitalet), which is situated in Copenhagen, has bacteremia episodes that are not captured by the DACOBAN database. We estimate that approximately $16 \%$ of bacteremic episodes among residents in the Capital Region occur at the Rigshospitalet, with a preponderance of nosocomial episodes among 0 - to 40-year-old patients occurring in highly specialized wards (such as oncology, hematology, or nephrology) in this hospital (unpublished data). We plan to include microbiological data from Rigshospitalet in the DACOBAN database after taking its different laboratory information system (MADS [http://www.madsonline.dk]) into account.

Therefore, the DACOBAN database covers all positive BCs from the North Denmark Region and approximately $84 \%$ of positive $\mathrm{BCs}$ from the Capital Region; given the distribution of BCs between these two regions in the DACOBAN database (data not shown), coverage is estimated to be $88 \%$. These two geographically and demographically well-defined administrative regions have a background population of approximately 1.7 million (32\% of Denmark's population, Table 1). ${ }^{5}$ Currently, the data cover the 12 -year period from January 1, 2000 through December 31, 2011.

In future, DACOBAN data will include positive BCs from additional municipalities in the Capital Region (background population approximately 0.3 million), which were incorporated into the Herlev catchment area in May 2013.

\section{Measures}

\section{Analytical units}

A BC set comprises a number of BC bottles drawn simultaneously from the patient (Table 1), and is the unit used in the literature to derive bacteremic episodes. ${ }^{11}$ We cannot derive
BC sets from the DACOBAN database, ${ }^{12}$ because each clinical microbiology department uses its own laboratoryspecimen numbering. Therefore, we have to use dates instead of $\mathrm{BC}$ sets, which is a reasonable assumption because BC bottles drawn on the same date presumably represent the same bacteremic episode. Using dates, we apply commonly used algorithms for contamination episodes based on the likelihood of a given microbial species to originate from the skin flora versus the bloodstream, ${ }^{11}$ characterizing the remaining $\mathrm{BCs}$ as representing true bacteremia. Therefore, we compute bacteremic episodes on the basis of consecutive dates of positive BCs. ${ }^{3,12}$

\section{Patients and bacteremic episodes}

Currently, the DACOBAN database includes 39,292 patients with 49,951 bacteremic episodes. The age-related incidences (Figure 1) and other main characteristics (Table 2) do not differ materially from bacteremic patients in other population-

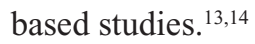

\section{Main categories and variables}

We divided the DACOBAN database into variables related to basic characteristics, microbiology, comorbidity, vital status, and physicians' supplementary variables (Table 3).

\section{Basic characteristics}

The best-estimate date represented the baseline date of the bacteremic episode. The start of the bacteremic episode was defined as the date of drawing the BC. However, the date of the draw was missing in 4,228 bacteremic episodes $(8.5 \%)$. We substituted the date of the draw with the date of $\mathrm{BC}$ receipt in clinical microbiology departments for these episodes. For the remaining 45,723 bacteremic episodes, $98.4 \%$ had $\leq 1$ day between the draw date and the receipt date. From 2013, the electronic requisition of all BCs in the Capital Region precluded missing draw dates. Bacteremic episodes and the acquisition of bacteremia were computer-derived ${ }^{12}$ on the basis of generally accepted criteria. ${ }^{11,15,16}$

\section{Microbiological data}

Detection systems (eg, different media or numbers of bottles) differ between clinical microbiology departments (Table 1) and over time within the same department. ${ }^{17}$ However, the main caveat relates to data on antibiotic resistance. The three departments have not coordinated on procedures, minimum inhibitory concentration values, or standard panels, yet all three departments participate in the same external quality-assessment schemes, primarily the UK National 


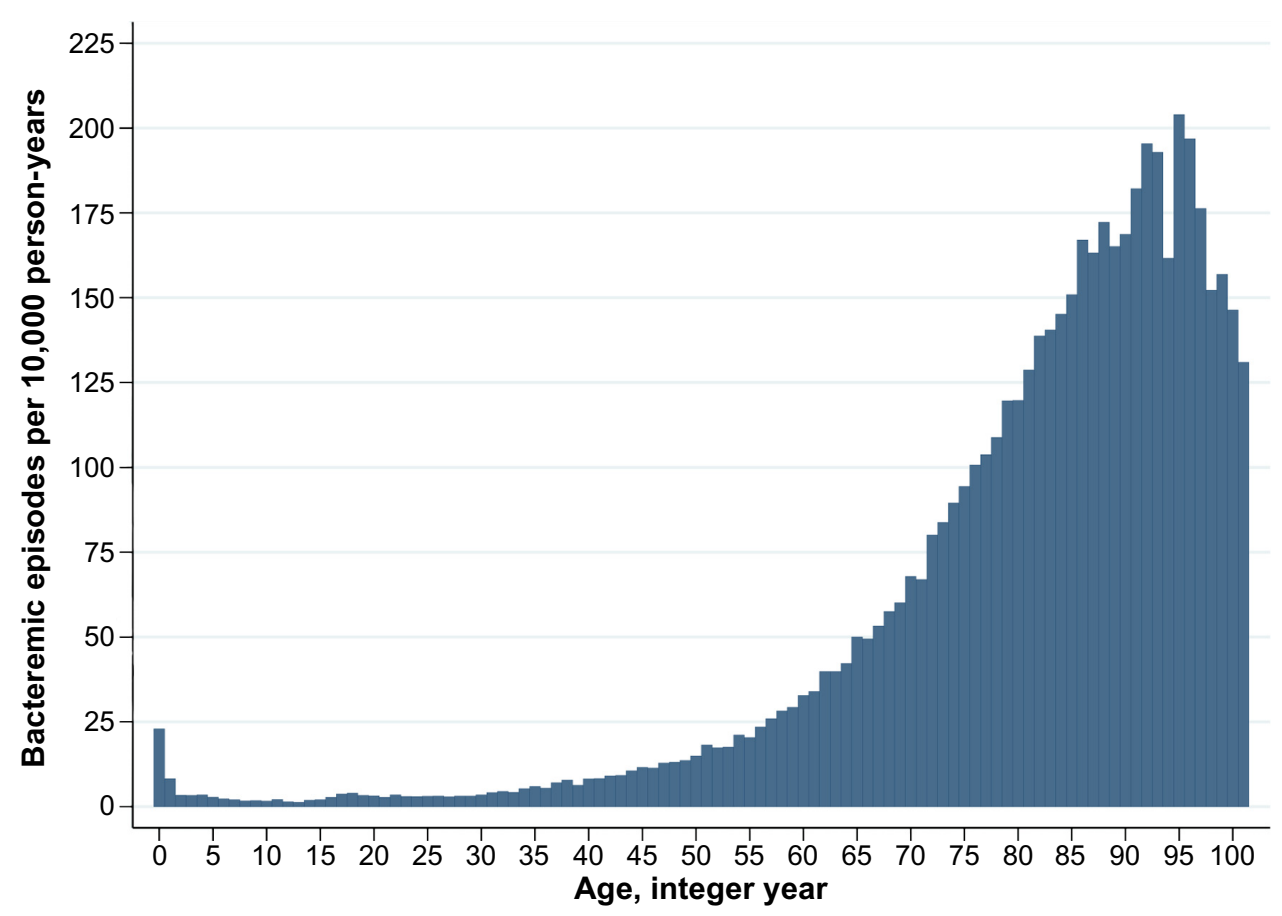

Figure I Age-related bacteremic episodes per 10,000 person years among 49,95I bacteremic episodes, 2000-20II. Each column covers I year. Age I0I-I06 years $(n=21)$ merged.

External Quality Assessment Service (http://www.ukneqasmicro.org.uk). Work is ongoing to evaluate past methods for antibiotic resistance that apply to all departments, but before this is implemented, generations of these data may differ between the departments, and caution in their interpretation is warranted.

\section{Comorbidity}

Comorbidity was assessed on the basis of the Charlson Comorbidity Index, in which 19 major disease categories (eg, malignancy, cardiovascular diseases, and diabetes mellitus) were assigned a score, with higher scores given to more severe diseases. ${ }^{18,19}$ We used the first-time diagnosis of a Charlson disease between 1977 (the year of implementation of the DNPR) and the best-estimate date. We had access to all DNPR data for DACOBAN patients, which enables individual linkage for studies comprising other comorbidities than those found in the Charlson Comorbidity Index, as well as surgical procedures.

\section{Vital status}

We had complete follow-up information for the vital status of all 39,292 patients except one. On the latest status date (September 27, 2012), 14,375 (36.6\%) patients were alive, eleven $(0.03 \%)$ had disappeared, $192(0.49 \%)$ had emigrated, and the remaining $24,713(62.9 \%)$ were deceased.

\section{Physicians' supplementary variables}

For part of the data (Aalborg, 2007-2008; Herlev, 2006-2011; Hvidovre, 2006-2008), covering 8,645 patients with 9,672 bacteremic episodes (19.4\%), physicians at the clinical microbiology departments prospectively recorded clinical data in an electronic database that is linked to the DACOBAN database. This enabled the retrieval of clinical data, such as possible focus of infection, empiric and final antibiotic treatment, and intravascular catheterization. These data represent routine assessments based on clinical data and information from positive microbiological specimens other than BCs that are generated by physicians at clinical microbiology departments in close cooperation with physicians at the clinical wards in which the patients were hospitalized. Variables related to antibiotic treatment were incorporated into an algorithm that determined whether the treatment was appropriate.

\section{Research from the database}

The population-based data and the high number of patients and bacteremic episodes make the DACOBAN database suitable for surveillance studies. ${ }^{5,7}$ DACOBAN data were recently included in a multinational surveillance study conducted by Laupland et al. ${ }^{5}$ The study included an unprecedentedly high number (ie, 18,430) of incident Staphylococcus aureus bacteremic episodes. Incidence rates with detailed 
Table 2 Main characteristics of the 49,95I bacteremic episodes, 2000-20II

\begin{tabular}{|c|c|}
\hline Characteristic & Number (\%) \\
\hline \multicolumn{2}{|l|}{ Age, years } \\
\hline $0-14$ & $\mathrm{I}, 577(3.2)$ \\
\hline $15-64$ & $16,743(33.5)$ \\
\hline $65-80$ & $17,577(35.2)$ \\
\hline$>80$ & I4,054 (28.I) \\
\hline Females & $23,078(46.2)$ \\
\hline \multicolumn{2}{|l|}{ Charlson Comorbidity Index score } \\
\hline 0 & I3,353 (26.7) \\
\hline $1-2$ & $18,702(37.4)$ \\
\hline$>2$ & 17,896 (35.8) \\
\hline \multicolumn{2}{|l|}{ Specialty ${ }^{a}$} \\
\hline Medical & $24,116(66.0)$ \\
\hline Surgical & $9,417(25.8)$ \\
\hline Pediatric & $\mathrm{I}, \mathrm{I} 49(3.2)$ \\
\hline Unknown & $\mathrm{I}, 848(5.1)^{\mathrm{b}}$ \\
\hline \multicolumn{2}{|l|}{ Clinical department ${ }^{\mathrm{a}}$} \\
\hline Bed unit & $32,298(88.4)$ \\
\hline Intensive care unit & $2,743(7.5)$ \\
\hline Emergency room & $804(2.2)$ \\
\hline Ambulatory & $602(1.7)$ \\
\hline General practitioner $^{c}$ & $12(0.0)$ \\
\hline Psychiatric & $28(0.1)$ \\
\hline Unknown & $43(0.1)$ \\
\hline \multicolumn{2}{|l|}{ Acquisition of bacteremia } \\
\hline Community & $20,218(40.5)$ \\
\hline Health care-related & $12,080(24.2)$ \\
\hline Nosocomial & $17,479(35.0)$ \\
\hline Unknown & $174(0.4)$ \\
\hline \multicolumn{2}{|l|}{ Group of microorganisms } \\
\hline Escherichia coli & 14,045 (28. $)$ \\
\hline Enterobacter spp. & 971 (1.9) \\
\hline Klebsiella spp. & $3,323(6.7)$ \\
\hline Other Enterobacteriaceae & $2,038(4.1)$ \\
\hline Pseudomonas aeruginosa & $1,340(2.7)$ \\
\hline Anaerobic Gram-negative bacteria & $\mathrm{I}, \mathrm{I} 43(2.3)$ \\
\hline Other Gram-negative bacteria & $1,357(2.7)$ \\
\hline Staphylococcus aureus & $6,238(12.5)$ \\
\hline Coagulase-negative staphylococci & $1,296(2.6)$ \\
\hline Streptococcus pneumoniae & $4,080(8.2)$ \\
\hline Hemolytic streptococci & $\mathrm{I}, 754(3.5)$ \\
\hline Enterococci & $2,433(4.9)$ \\
\hline Other Gram-positive bacteria & $2,417(4.8)$ \\
\hline Gram-positive rods & $1,057(2.1)$ \\
\hline Fungi & $\mathrm{I}, 745(3.5)$ \\
\hline Polymicrobial & $4,298(8.6)$ \\
\hline Unknown ${ }^{d}$ & $416(0.8)$ \\
\hline
\end{tabular}

Notes: aWhen the blood culture was drawn; only covers the 36,530 bacteremic episodes from 2000 through 2008 because 2009-201I data have not yet been mapped; 'bl,705 of these $(92.3 \%)$ were from intensive care units; 'the general practitioner does not represent a clinical department, but this was recorded for only 16 of 49,95 I bacteremic episodes $(0.03 \%)$, indicating that virtually all bacteremia patients were hospitalized; ' ${ }^{m}$ mainly due to lack of speciation.

information on regional differences were reported separately for community-acquired and nosocomial bacteremias and methicillin-resistant and methicillin-susceptible episodes from developed countries on three continents during a 9-year period. Another cohort study of enterococci based on data from DACOBAN revealed some clinically relevant findings on infective endocarditis in $25 \%$ of adult patients with Enterococcus faecalis bacteremia. ${ }^{7}$ We also found that only $17.7 \%$ of patients with E. faecalis and $7.4 \%$ with E. faecium bacteremia received appropriate antimicrobial therapy within the first day after admission.

In a study using the physicians' supplementary variables as the gold standard, we assessed the validity of computerderived algorithms for contamination versus bacteremic episodes, and among episodes of bacteremia, their acquisition (ie, community, health care-related, or nosocomial) and whether they were monomicrobial or polymicrobial. ${ }^{12}$ The results showed high validity for contamination versus bacteremia and for monomicrobial versus polymicrobial bacteremia, but they were less reliable for acquisition.

Koch et al used the unique civil registration number to link DACOBAN data to socioeconomic variables maintained by Statistics Denmark, generating the first bacteremia study showing that low income, low level of education, and low social status were all strong predictors of higher 30-day mortality. ${ }^{20}$ The same authors matched 4,117 communityacquired bacteremia patients by sex, age, and residency to 41,170 population controls to assess socioeconomic status as a risk factor for bacteremia. ${ }^{21}$ Low education and low income rendered up to a $70 \%$ increased risk of bacteremia, even after adjusting for preexisting chronic diseases and drug and alcohol abuse.

Part of the DACOBAN data overlap the North Denmark Bacteremia Research Database, which is a well-established research database with prospectively derived data (eg, focus on infection and antibiotic treatment) that has been the source of roughly 60 publications. ${ }^{9}$ Linkage to this database enables studies that supply clinical data and further validate the retrospective data of the DACOBAN database.

\section{Strengths and weaknesses}

The main strengths of the DACOBAN database are its catchment area of well-defined geographic regions with valid population statistics, the high number of patients, the ability to distinguish between incident and nonincident bacteremic episodes due to the patients' longitudinal data, the possibility of complete follow-up for both short-term and long-term mortality, and the flexibility of linking to other administrative registries or research databases. Because patients are recruited from a well-defined geographic/demographic region, the DACOBAN database fulfills one prerequisite for participating in the multinational bacteremia collaborative network. The estimated coverage of $88 \%$ almost fulfills the 
Table 3 Main variables

\begin{tabular}{|c|c|c|}
\hline Main group & Variable & Description/comments \\
\hline \multirow[t]{12}{*}{ Basic characteristics } & Civil registration number & $\begin{array}{l}\text { Unique personal identification number given to all Danish } \\
\text { residents }\end{array}$ \\
\hline & DACOBAN region & Aalborg, Herlev, or Hvidovre \\
\hline & Retrieval date of $B C$ & \\
\hline & Receipt date of BC at department of clinical & \\
\hline & microbiology & \\
\hline & Best-estimate date & Retrieval date; if this was missing, receipt date (never missing) \\
\hline & Date of admission & For the bacteremic episode \\
\hline & Date of discharge & For the bacteremic episode \\
\hline & Clinical specialty that retrieved the $B C$ & Medical, surgical, pediatric, or unknown \\
\hline & Clinical department that retrieved the $B C$ & $\begin{array}{l}\text { Bed unit, intensive care unit, emergency room, ambulatory, } \\
\text { general practitioner }{ }^{\mathrm{a}} \text {, psychiatry, or unknown }\end{array}$ \\
\hline & Number of bacteremic episodes for each patient & Numbered chronologically \\
\hline & Acquisition of bacteremia & Community, health care-related, nosocomial \\
\hline \multirow[t]{2}{*}{ Microbiology } & Microorganism & Each species is given a unique number \\
\hline & Antibiotic-resistance data & $\begin{array}{l}\text { As criteria differ between DACOBAN regions data should } \\
\text { be interpreted with caution }\end{array}$ \\
\hline \multirow[t]{2}{*}{ Comorbidity } & Charlson Comorbidity Index points & \\
\hline & $\begin{array}{l}\text { Date of earliest diagnosis of Charlson comorbid } \\
\text { condition }\end{array}$ & As from 1977 \\
\hline \multirow[t]{2}{*}{ Vital status } & Status & Alive, disappeared, emigrated, or deceased \\
\hline & Status date & Updated September 27, 2012 \\
\hline \multirow[t]{16}{*}{ Physicians' supplementary variables } & Clinical department at first notification & \\
\hline & Clinical department that retrieved the $\mathrm{BC}$ & \\
\hline & Foreign bodies & \\
\hline & Allergy & \\
\hline & Contamination or bacteremic episode & \\
\hline & Acquisition of bacteremia & Community, health care-related, nosocomial \\
\hline & Focus of infection & \\
\hline & Immunosuppression & \\
\hline & Comorbidity & \\
\hline & Surgery performed & Yes versus no \\
\hline & Catheter treatment(s) & \\
\hline & Antibiotic treatment, first notification & \\
\hline & Antibiotic recommendation, first notification & \\
\hline & Antibiotic treatment, second notification & \\
\hline & Antibiotic recommendation, second notification & \\
\hline & Antibiotic treatment appropriate & \\
\hline
\end{tabular}

Note: ${ }^{a}$ The general practitioner does not represent a clinical department, but this was recorded only for 16 of 49,951 bacteremic episodes ( $\left.0.03 \%\right)$, indicating that virtually all bacteremia patients were hospitalized.

Abbreviations: DACOBAN, Danish Collaborative Bacteraemia Network; BC, blood culture.

other prerequisite stating that $\geq 90 \%$ of positive BCs have to be identified. In general, we think that the population-based principles are fulfilled, but unpublished data indicate that for the lower catchment in the Capital Region, caution is warranted in interpreting nosocomial bacteremic episodes among 0 - to 40-year-old patients from this region. Such episodes comprised 2,989 of the 49,951 DACOBAN database episodes $(6 \%)$.

The high number of patients enables precise statistical measures, and is advantageous for the study of rare microorganisms, which are often difficult to find in sufficient numbers among data from single clinical wards. Thus far, the DACOBAN database covers 12 years, an appropriate time span for studying longitudinal aspects, such as the recurrence of bacteremic episodes ${ }^{22}$ or the incidence of microorganisms related to changes in laboratory procedures. ${ }^{17}$

Most prognostic bacteremia studies report only inhospital mortality, mainly because mortality after discharge is difficult to obtain in most non-Scandinavian countries. In-hospital mortality is heavily influenced by the length of admission. The DACOBAN database enables time-derived follow-up periods, such as 30-day or 365-day mortality. The Danish Civil Registration System is virtually $100 \%$ accurate, which also applies to the date of death. ${ }^{6}$

The civil registration number facilitates linkage to other registries, including the retrieval of matched controls from the 
background population using incidence-density sampling. ${ }^{23}$ It also enables the retrieval of supplementary data from clinical microbiology departments, such as information on negative $\mathrm{BCs}^{24}$ or other specimen types. Further examples include socioeconomic data as described earlier, redemptions of prescribed drugs from pharmacies, ${ }^{25}$ and the more than 50 nationwide clinical databases that cover specific disease entities, interventions, or activities. ${ }^{26}$

The lack of clinical and paraclinical data related to the acute illness encountered in bacteremia patients constitutes the main limitation of the DACOBAN database. Clinical data, apart from discharge diagnoses found in the DNPR, are not recorded electronically and are very labor-intensive to obtain. Paraclinical data, however, are recorded electronically in all hospitals. The recent compilation of all paraclinical data into an accessible nationwide electronic registry by actors outside of the DACOBAN group offers new unique opportunities, in contrast to earlier studies in which linking data to paraclinical data from the individual hospital was the only option. ${ }^{27,28}$

The clinical data in the DACOBAN database mainly relate to chronic diseases exemplified by the Charlson Comorbidity Index, which is commonly used and validated for prognostic purposes. ${ }^{19}$ The DNPR is less accurate than the Danish Civil Registration System, and has undergone changes of which the researcher should be aware. ${ }^{8}$ However, the computation of previous comorbid conditions as a summary adjustment measure in prognostic models is sufficient.

The physicians' supplementary variables described earlier yield information on important clinical aspects related to the bacteremic episode, such as the possible focus of infection, the appropriateness of the antibiotic treatment, and whether the patient was intravascularly catheterized. However, care is warranted in interpreting these data, as they represent numerous physicians' routine assessments, with no evaluation of interobserver agreement or the use of formally specified criteria. ${ }^{12}$ Despite the fact that the supplementary variables have been included for only a limited period of time, the source data are recorded continuously as an integral part of the physicians' documentation of contacts with the patients' clinical teams. With more effective methods for handling data on the patient's clinical state, the possible foci of infection, and clinical decision making, such data could become a valuable part of the DACOBAN database in the future.

Another limitation relates to the possible inaccuracy in determining bacteremic episodes from an array of positive BCs. ${ }^{22,29}$ We partly evaluated the validity of the computer algorithms used for this purpose, ${ }^{12}$ but more work is required to assess its robustness, such as in prognostic models.

\section{Data-resource access}

Interested collaborators are encouraged to mail the corresponding author, who will forward the request to the DACOBAN steering committee (HCS, MA, JDK, and CØ). Linkage to other registries has to be performed by the DACOBAN group, as the civil registration number will be encrypted prior to data delivery, in accordance with Danish legislation. The DACOBAN database was approved according to the guidelines of the Regional Committee on Health Research Ethics for use of clinical and laboratory data (Danish Data Protection Agency, record 2007-41-0627). Additional permissions from the Danish Data Protection Agency will be required for external collaborators.

\section{Acknowledgments}

Contributing members of DACOBAN: Christian Østergaard (Department of Clinical Microbiology, Hvidovre Hospital, Copenhagen University Hospital, Copenhagen, Denmark), Magnus Arpi (Department of Clinical Microbiology, Herlev Hospital, Copenhagen University Hospital, Copenhagen, Denmark), Kim Oren Gradel (Center for National Clinical Databases - South, Odense University Hospital, Odense, Denmark), Ulrich Stab Jensen (Department of Clinical Microbiology, Copenhagen University Hospital, Rigshospitalet, Copenhagen, Denmark), Sara Thønnings (Department of Clinical Microbiology, Copenhagen University Hospital, Rigshospitalet, Copenhagen, Denmark), Jenny Dahl Knudsen (Department of Clinical Microbiology, Hvidovre Hospital, Copenhagen University Hospital, Copenhagen, Denmark), Kristoffer Koch (Department of Clinical Microbiology, Aalborg University Hospital, Aalborg, Denmark), Mette Pinholt (Department of Clinical Microbiology, Herlev Hospital, Copenhagen University Hospital, Copenhagen, Denmark), Jesper Smit (Department of Clinical Microbiology, Aalborg University Hospital, Aalborg, Denmark), Henrik Carl Schønheyder (Department of Clinical Microbiology, Aalborg University Hospital, Aalborg, Denmark), Mette Søgaard (Department of Clinical Epidemiology, Institute of Clinical Medicine, Aarhus University Hospital, Aarhus University, Aarhus, Denmark).

\section{Disclosure}

The authors report no conflicts of interest in this work.

\section{References}

1. Goto M, Al-Hasan MN. Overall burden of bloodstream infection and nosocomial bloodstream infection in North America and Europe. Clin Microbiol Infect. 2013;19:501-509.

2. Schønheyder HC, Paul M. Placing the burden of bacteraemia in perspective. Clin Microbiol Infect. 2013;19:489-491. 
3. Weinstein MP, Reller LB, Murphy JR, Lichtenstein KA. The clinical significance of positive blood cultures: a comprehensive analysis of 500 episodes of bacteremia and fungemia in adults. I. Laboratory and epidemiologic observations. Rev Infect Dis. 1983;5:35-53.

4. Laupland KB, Schønheyder HC, Kennedy KJ, et al. Rationale for and protocol of a multi-national population-based bacteremia surveillance collaborative. BMC Res Notes. 2009;2:146.

5. Laupland KB, Lyytikainen O, Søgaard M, et al. The changing epidemiology of Staphylococcus aureus bloodstream infection: a multinational population-based surveillance study. Clin Microbiol Infect. 2013;19: $465-471$.

6. Pedersen CB. The Danish Civil Registration System. Scand J Public Health. 2011;39:22-25.

7. Pinholt M, Østergaard C, Arpi M, et al. Incidence, clinical characteristics and 30-day mortality of enterococcal bacteraemia in Denmark 2006-2009: a population-based cohort study. Clin Microbiol Infect. 2014;20:145-151.

8. Lynge E, Sandegaard JL, Rebolj M. The Danish National Patient Register. Scand J Public Health. 2011;39:30-33.

9. Schønheyder HC, Søgaard M. Existing data sources for clinical epidemiology: the North Denmark Bacteremia Research Database. Clin Epidemiol. 2010;2:171-178.

10. Olsen J, Basso O, Sørensen HT. What is a population-based registry? Scand J Public Health. 1999;27:78.

11. Trick WE, Zagorski BM, Tokars JI, et al. Computer algorithms to detect bloodstream infections. Emerg Infect Dis. 2004;10:1612-1620.

12. Gradel KO, Knudsen JD, Arpi M, Østergaard C, Schønheyder HC, Søgaard M. Classification of positive blood cultures: computer algorithms versus physicians' assessment - development of tools for surveillance of bloodstream infection prognosis using population-based laboratory databases. BMC Med Res Methodol. 2012;12:139.

13. Uslan DZ, Crane SJ, Steckelberg JM, et al. Age- and sex-associated trends in bloodstream infection: a population-based study in Olmsted County, Minnesota. Arch Int Med. 2007;167:834-839.

14. Skogberg K, Lyytikäinen O, Ollgren J, Nuorti JP, Ruutu P. Populationbased burden of bloodstream infections in Finland. Clin Microbiol Infect. 2012;18:E170-E176.

15. Garner JS, Jarvis WR, Emori TG, Horan TC, Hughes JM. CDC definitions for nosocomial infections, 1988. Am J Infect Control. 1988;16: $128-140$.

16. Friedman ND, Kaye KS, Stout JE, et al. Health care-associated bloodstream infections in adults: a reason to change the accepted definition of community-acquired infections. Ann Int Med. 2002;137:791-797.
17. Søgaard M, Engebjerg MC, Lundbye-Christensen S, Schønheyder HC. Changes in blood culture methodology have an impact on time trends of bacteraemia: a 26-year regional study. Epidemiol Infect. 2011;139: 772-776.

18. Charlson ME, Pompei P, Ales KL, MacKenzie CR. A new method of classifying prognostic comorbidity in longitudinal studies: development and validation. J Chronic Dis. 1987;40:373-383.

19. de Groot V, Beckerman H, Lankhorst GJ, Bouter LM. How to measure comorbidity. a critical review of available methods. J Clin Epidemiol. 2003;56:221-229.

20. Koch K, Nørgaard M, Schønheyder HC, Thomsen RW, Søgaard M. Effects of socioeconomic status on mortality after bacteremia in working-age patients. A Danish population-based cohort study. PLoS One. 2013;8:e70082.

21. Koch K, Søgaard M, Nørgaard M, Thomsen RW, Schønheyder HC. Socioeconomic inequalities in risk of hospitalization with communityacquired bacteremia: a Danish population-based case-control study. Am J Epidemiol. 2014;179(9):1096-1106.

22. Jensen US, Knudsen JD, Østergaard C, Gradel KO, FrimodtMøller N, Schønheyder HC. Recurrent bacteraemia: a 10-year regional population-based study of clinical and microbiological risk factors. J Infect. 2010;60:191-199.

23. Wacholder S, Silverman DT, McLaughlin JK, Mandel JS. Selection of controls in case-control studies. III. Design options. Am J Epidemiol. 1992;135:1042-1050.

24. Søgaard M, Nørgaard M, Pedersen L, Sørensen HT, Schønheyder HC. Blood culture status and mortality among patients with suspected community-acquired bacteremia: a population-based cohort study. BMC Infect Dis. 2011;11:139.

25. Kildemoes HW, Sørensen HT, Hallas J. The Danish National Prescription Registry. Scand J Public Health. 2011;39:38-41.

26. Green A. Danish clinical databases: an overview. Scand J Public Health. 2011;39:68-71.

27. Gradel KO, Thomsen RW, Lundbye-Christensen S, Nielsen H, Schønheyder HC. Baseline C-reactive protein level as a predictor of mortality in bacteraemia patients: a population-based cohort study. Clin Microbiol Infect. 2010;17:627-632.

28. Grann AF, Erichsen R, Nielsen AG, Froslev T, Thomsen RW. Existing data sources for clinical epidemiology: the clinical laboratory information system (LABKA) research database at Aarhus University, Denmark. Clin Epidemiol. 2011;3:133-138.

29. Roberts FJ. Definition of polymicrobial bacteremia. Rev Infect Dis. 1989;11:1029-1030.
Clinical Epidemiology

\section{Publish your work in this journal}

Clinical Epidemiology is an international, peer-reviewed, open access journal focusing on disease and drug epidemiology, identification of risk factors and screening procedures to develop optimal preventative initiatives and programs. Specific topics include: diagnosis, prognosis, treatment, screening, prevention, risk factor modification, systematic

\section{Dovepress}

reviews, risk \& safety of medical interventions, epidemiology \& biostatical methods, evaluation of guidelines, translational medicine, health policies \& economic evaluations. The manuscript management system is completely online and includes a very quick and fair peer-review system, which is all easy to use. 